\title{
SOBRE EL CAMPO SEMÁNTICO DEL TÉRMINO "BA- CHILLER" EN ÉPOCA MEDIEVAL
}

\author{
Lorenzo MARTINEZ ANGEL \\ Universidad de León
}

Intoresados por el tema de la cducación en época medieva] ${ }^{1}$ reparamos en que el campo semántico del término "bachiller" es insulicientemente conocido. Intentaremos en este breve trabajo prolundizar en el tema.

En el Diccionario de Autoridades se recoge el significado que posee en el mundo académico, como "El primer grado que se dá en las Universidades à los que han oído y estudiado alguna facultád: como Artes, Theología, Leyes, Cánones, Medicina, despues de haver cursado en ellas el tiempo determinado para recibirle. Viene del Latino Baccalaureus, que es lo mismo que laureado con bacas, porque à los que reciben estos grados en lo antiguo los coronaban con laurél con las frutillas ò bacas que lleva."2 Las otras acepciones también se refieren al mundo académico, salvo la irónica: "Comunmente, y por vilipéndio se då este nombre, y se entiende por que el habla mucho fuera de propósito, y sin fundamento. ${ }^{n}$ Estos valores perduran en el castellano de nuestros días 5 .

Obviamente no pretendemos negar la acepción académica del término "bachiller", de la que nos dan informaciones tanto las fuentes documentales como las literarias, pues en algunas de sus obras escritores de la talla del gran humanista Juan Luis Vives, por citar simplemente un nombre, se ocupan del tema".

1 Interés plasmado en trabajos como:

-Instituciones educativas medievales leonesas. La escuela caledralicia: Estudios Ilumanísticos (Geografia. Historia. Arte) 18 (1996) 147-160.

-Aproximación a la escuela catedralicia de Segovia y a sus maestrescuelas (siglos XII-XII): Memoria Ecclesine 12 (1998) 63-69.

${ }^{2}$ Diccionario de Autoridades, Madrid 1984 (edición facsimil de la origina! publicada en Madrid en 1726), päg. 527.

${ }^{3}$ Aunque indirectamente sí habría relación.

+ Diccionario de Autoridades, $l$. c.

s Real Academia Española, Diccionario de la Lengua Española. Madrid 1992. pág. 175: "bachiller. (Del fr. bachelier.) com. Persona que ha recibido el primer grado académico que se otorgaba antes a los estudiantes de facultad, y que ahora se concede en las de teología y derecho canónico en los seminarios. / 2 . Persona que ha obtenido ol grado que concede al terminar la segunda enseñanza. / en artes. bachiller, persona que ha recibio el primer grado académico." temente."

La acepción irónica es la segunda: "Persona que habla mucho e impertinen-

" "De la misma manera en la palestra literaria de P’arís, se comenzó a llamar adelantado o bachiller a quien habia disputado ya puiblicamente sobre cualquier arte 
Pero el significado no era exclusivamente el indicado, y el olvido de una parte substancial del campo semántico hace que casi automáticamente se identifique esta palabra con el grado académico ${ }^{7}$.

Sobre el término que nos ocupa es interesante un texto de María Angeles Galino, conocida experta en Historia de la Educacion: "Existia todavia otro grado inferior. Hasta los quince años el estudiante no podía hacer otra cosa que estudiar; pero a partir de esa edad podia empezar a ensayarse en los trabajos de la enseñanza, a la vez que continuaba preparándose para el doctorado. El paso de una etapa a otra estaba señalado por una especie de inceptio inferior, parecida a la del doctorado. Recibia el nombre de determinance, del latin determinare, que equivale a sostener tesis. (...) La determinatio constituyó. pues, un tercer grado. que, al parecer desde el siglo XV, se conoció con el nombre de buchillerato: la palabra bachiller se empleaba ya desde tiempos atrás en los gremios de oficios y en la caballeria para designar el joven que ocupaba una categoría intermedia entre el caballero y el escudero."

La cronología del siglo XV indicada debe ser relativizada, ya que conocemos algún estudio que indica que su utilización era anterior al siglo $X V^{\prime \prime}$.

Ante esto, podemos preguntarnos si las instituciones con denominaciones como, por ejemplo, "Bachilleres de la iglesia de León" o "Bachilleres de la iglesia de Santa Maria" (como sucede en León desde, por lo menos, los comienzos del siglo $\mathrm{XlII}{ }^{10}$ ) 5 e corresponden a clérigos con título académico

o disciplina." (Diálogos sobre la educacion, citado en Enrique GONZALEZ, VICTOR GUTIERREZ, Las Universidades renacentistas, Madrid 1985, pág. III de los "Textos").

${ }^{7}$ Por ejemplo, puede verse esta identificación en un magnílico trabajo sobre títulos acadėmicos: Taurino BURON CASTRO. Títulos académicos: Signo 4 (1997) 187-206; concretamente en la pág. 194, en la nota $n^{\circ} .11$, se dice, tras hablar del título académico de bachiller: "También existo en León una comunidad eclesiástica medieval, que adopta el nombre de Comunidad de Bachilleres del Ciento y otra institución. dedicada al canto, dentro de la Catedral..." Consideramos que en ambos casos no debe relacionarse el término bachiller con el grado académico, como intentaremos demostrar.

${ }^{8}$ Maria Angeles GALlNo, Historia de la Educación. Edades Antigua y Media, Madrid 1988, pág. 541.

${ }^{17}$ Como ejemplo podemos cittar el siguiente: E. KWANTEN, Le Collège SaintBernardà Paris. Sa fondation et ses débuts; Revue d'Histoire Ecelésiastique 43 (1948) 443-472. Concretamente, en la pég. 466, se cita la siguiente inscripción referida a un monje cisterciense: “Ilic sepulta sunt intestina D. Himberti, abbatis Prulliacensis, bachalarii in theologia, qui decessit MCCLXXXXVIII pridie idus martii". Aunque no se indica en el estudio la fecha de realización de la inscripción (es decir, si es original de la época), hemos de tener en cuenta que se refiere a alguien que obtuvo su título en París, el más importante centro del saber de su tiempo y una de las primeras universidades en ser fundada, por lo que nada extrañaría que en su seno la terminologia de los títulos se hubiera concretado en épocas tempranas.

No obstante, todas estas cuestiones necesitan estudios mís profundos. 
o simplemente el término "bachiller" indica la pertenencia a una cofradia u otro tipo de agrupación.

Por lo que se refiere a los casos concretos que mencionamos ${ }^{11}$, conocemos referencias al tórmino "bachiller" al menos desde comienzos del siglo XIII, como ya indicamos'2. Está constatado que el Cabildo de la Catedral de Santa María de Regla envió a miembros del mismo a estudiar a la Univer-

10 Pero también en otros lugares, como, por ejemplo, Astorga. Así, sobre la Cofradia de los benefíciados de San Nicolás en época medieval se ha escrito: "Fundada en Ja capilla de San Nicolás de Bari, en los claustros de la catedral vieja, detrás de la capilla de Santa Marina, esta estructura corporativa acogía a los bachilleres o beneliciados, inicialmente colradía de clérigos.

Documentalmente la encontramos por primera vez en 1367..." (Gregorin CAVERo DOMINGUEZ, Las cofradias en Astorga durante la Edad Media. Zamora 1992, pág. 64.

11 Sobre esto se ha escrito lo sigulente: "Cofradia o Compañia de los Bachilleres. |...। Ya desde 1120, pero mejor desde las constituciones de Honorio III del 27 de mayo de 1224 conocemos la existencia de doce bachilleres en la catedral de León, su organización y olsligaciones, cuya existencja llega hasta el siglo XIX. Sin embargo, no se debiơ reducir a éstos la cofradía que estamos estudiando, ya que Aldonza Martínez de Mayorga en su testamento del 11 de agosto de 1382 "mando a los cient bachilleres de la çibdad de Leon mill maravedis con tal condicion que ellos me resçiban por su cofrada et que me entierren e me lieven $e$ me fagan toda onrra a mi sepultura segunt que fasen a cada uno de sus cofrades clerigos e canonigos a compañeros de la dicha iglesia de Leon. La colradía. pues, de los bachilleres se componía de cien clérigos, recibiendo por cofrades, como ocurria en todas las cofradías a cualquier persona: clérigo o laico, hombre o mujer, que a la hora de la muerte les hiciera alguna manda con que celebrar honras fúnebres en su sufragio." (Jose SANCHEZ HERRERO, Las diócesis del Reino de León. León 1978, pág. 442).

Esto testimonin la confusión que existe entre las denominaciones de "Bachilleres del Ciento" y "Bachilleres de los Doce". Sería destacablo una profundización en el estudio, para clarificar totalmente si se deben identificar, o no, o hasta qué punto, ambas expresiones con una misma realidad. Así, en la nota $\mathrm{n}^{\mathrm{n}}$. 7 el texto aducido da a entender que se consideran como realidades distintas, mientras que José María Fernández Catón (Catálogo del Archivo llistórico Diocesano de León, I, León 1979, pág. 395) indica como referida a la "Comunidad del Ciento" Ia parte de un trabajo que Tomés Viltacorta dedica a los "Bachilleres de los Doce". No obstante, es una cuestión ajena a la finalidad de estas péginas, pues lo que nos ocupa es el anailisis del término "bachiller", aunque nos inclinamos por considerar que son dos instituciones distintes, aunque sỏlo sea por una razón funcional, pues difieren sus finalidades, y aunque puedan ser una misma, al menos en origen (lo que ignoramos), cuanto menos hay una duplicidad en su funcionalidad y en su denominación, Jo que nos lleva a la opinión indicada, aunque, evidentemente habrá que esperar investigaciones més profundas que den respuestas claras.

12 Respecto a la documentación, se pueden citar algunos ejemplos:

-Jose Maria FERNANDEZ CATON, Colección documental del Archivo de la Catedral de León (775-1230). V (1188-1230), León 1991, doc. $n^{\circ}$. 1956 11228-1230]; "Mando bachalarii Sante Marie hereditatem meam et vineas de Vanuncias, tali pacto quod lohannes, sobrino meo, et mater sua habeant in vita sua et dent vnoquoque ano pro aniverssario meo quatuor soldos dictis bachalariis, post mortem vero ipsam predictam hereditatem remaneat bachalarii Sante Marie pro atiluerssario meo”. En el 
sidad de Salamanca desde el mismo siglo XIII, al menos desde finales de esta centuria, por lo que conocemos ${ }^{13}$, pero teniendo en cuenta no sólo la cronologia aducida para el término "bachiller" como título académico"4, sino también la de los establecimientos universitarios en la Peninsula Ibérica y, sobre todo, los fines de las instituciones leonesas que analizamos, es más que probable que a comienzos del siglo XIIl la palabra debiera tener otro signilicado distinto del académico en los casos documentados en León.

Si atendemos a los "Bachilleres de los Doce" vemos una agrupación sacerdotal con fines litúrgico-musicales en el culto catedralicio, y si nos fijamos en los "Baclilleres del Ciento" se puede interpretar que la institución consiste en una cofradía con fines espirituales y sociales ${ }^{15}$. Por ello, quizá se haya producido un préstamo lingüístico de lo que en el mundo lajco eran los gremios a las corporaciones eclesiásticas indicadas, por lo que consideramos que en estos casos "bachiller" presenta un campo semántico indicativo a la pertenencia a una agrupación o cofradía eclesiástica, y no al hecho de haber obtenido el grado más bajo de los estudios universitarios ${ }^{\text {t6 }}$.

Evidentemente estas consideraciones se centran en los "Bachilleres de los

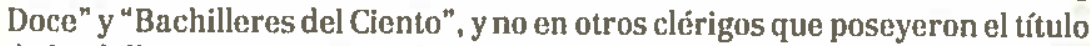
de bachiller tras su paso por las aulas, aunque de épocas posteriores, y cuya presencia es clara en documentos e inscripciones medievales leonesas.

Esperamos que estas lineas, en su sencillez, contribuyan a despertar el interés por la educación medieval en la Península Ibérica, al menos por lo que se refiere a cuestiones terminológicas.

doc. $n^{\text {" }}$. 1973, fochado el 25 de junio de 1230, aparece "Garsias Petri, bacallarius". Etc. -ID. Catálogo del Archivo IItstórico Diocesano de León. 1, Fondo Bachillores del Ciento, doc. $n^{\circ} .12$ (enero de 1231): "societati clericorum sedis Legionen ecclesio, qui baccallarii nuncupantur" $1 \ldots 1$ "Petro Iohannis predictorum baccallariorum preposito existente. l... Domno Marcus et Petrus Rosinol, baccallarii."

13 J. M. RUIZ ASENCIO. J. A. MARTIN FUERTES, Colección documental del archivo de la Catedral de León. IX (1269-1300), León 1994, doc. n. 2328, fechado el 9 de junio de 1273.

${ }^{14}$ Que. como vimos, no debe ser tenida en cuenta de forma literal.

${ }^{15}$ Cabe recordar lo que escribe el Dr. Fernández Catón: "...es interesante toda esa serie de fundaciones de memorias de misus y de aplicaciones sociales, a cuyos fines los donantes ofrecen sus bienes y hacienda a la Comunidad, haciendo de ésta una institución eminentemente espiritual y social." (Catalogo de Archivo Histórico Diocesano, I, pág. 395).

En obra citada de la Dra. Cavera se estudian las cofradias de clérigos (pägs. 49-51), con informaciones que harän comprender mojor el caso leonés.

14 De hecho, este término se adoptó porque en época medieval los estudiantes y maestros universitarios constituían un gremio: "Lsta serie de exámenes responde al hecho de que el gremio de estudiantes y maestros, al igual que los de menestrales y mercaderes, es un cuerpo cerrado que solamente abre sus puertas a aquellos que demuestran estar en posesión de las cualidades exigidas." (María Angeles GALINO. l.c.) 